\title{
Adherence to treatment assessed with the Adherence in Chronic Diseases Scale in patients after myocardial infarction
}

This article was published in the following Dove Press journal:

Patient Preference and Adherence

\author{
Agata Kosobucka' \\ Piotr Michalski' \\ Łukasz Pietrzykowski' \\ Michał Kasprzak ${ }^{2}$ \\ Karolina Obońska ${ }^{2}$ \\ Tomasz Fabiszak ${ }^{2}$ \\ Mirosława Felsmann ${ }^{3}$ \\ Aldona Kubica' \\ 'Department of Health Promotion, \\ Collegium Medicum, Nicolaus \\ Copernicus University, Bydgoszcz, \\ Poland; ' 2 Department of Cardiology \\ and Internal Diseases, Collegium \\ Medicum, Nicolaus Copernicus \\ University, Bydgoszcz, Poland; \\ ${ }^{3}$ Laboratory of Basic Clinical Skills \\ and Medical Simulations, Collegium \\ Medicum, Nicolaus Copernicus \\ University, Bydgoszcz, Poland
}

Introduction: A substantial subset of patients after myocardial infarction (MI) discontinue pivotal medication early after discharge. In particular, cessation of antiplatelet treatment may lead to catastrophic ischemic events. Thus, adherence to prescribed medication in patients after $\mathrm{MI}$ is an issue of medical and social concern.

Purpose: The aim of the study was to evaluate the level of adherence to treatment using a newly developed scale in patients after MI treated with percutaneous coronary intervention.

Patients and methods: A single-center, prospective, observational cohort clinical study with a 6-month follow-up was performed. Patients with physical or cognitive impairment, prisoners, soldiers, and family members and coworkers of the researchers were excluded from the study. The impact of selected sociodemographic and clinical factors on adherence was evaluated in 221 patients (63 women and 158 men) aged 30 to 91 years.

Results: The results obtained with the Adherence in Chronic Diseases Scale (ACDS) ranged from 7 to 28 points; with the average and median scored being 23.35 and 24, respectively. The ACDS score reflects the level of adherence to prescribed medication. The high ACDS scores ( $>26$ points) were obtained in $59(26.7 \%)$ patients, intermediate scores (21-26 points) in 110 $(49.8 \%)$ and low scores ( $<21$ points) in 52 subjects (23.5\%). Acute coronary syndrome (re-ACS) occurred in $18(8.1 \%)$ patients during the follow-up period. The high-level adherence (ACDS score $>26$ points) was found in $11.1 \%$ of patients with re-ACS vs $28.4 \%$ of the remaining ones $(P=0.1)$. Lower scores (mean \pm standard deviation) in re-ACS patients were found for items 2 and 3 of the ACDS: $3.11 \pm 0.68$ vs $3.45 \pm 0.73(P=0.02)$ and $3.28 \pm 0.89$ vs $3.64 \pm 0.64(P=0.04)$, respectively.

Conclusion: Age and previous MI were found to be independent factors influencing adherence assessed with the ACDS.

Keywords: adherence, myocardial infarction, coronary artery disease, antiplatelet treatment

\section{Introduction}

The World Health Organization (WHO) indicates coronary artery disease (CAD) as the leading cause of worldwide mortality. ${ }^{1}$ Despite the development of diagnostic techniques and increasingly improved treatment strategies, CAD remains a serious health, social and economic problem. ${ }^{2}$ Although playing pivotal roles, a proper diagnosis and implementation of recommended medication alone are not sufficient to achieve optimal results of treatment. The physician-patient collaboration and adherence to recommended treatment is essential to achieve intended therapeutic effect. ${ }^{3,4}$ Adherence to treatment is defined as "the extent to which the patient's behavior is consistent with recommendations regarding medication, diet, and lifestyle modification." ${ }^{5}$ According to
Correspondence: Agata Kosobucka Department of Health Promotion, Collegium Medicum, Nicolaus

Copernicus University, Lukasiewicza St I, 85-82I Bydgoszcz, Poland

Tel +48525855806

Email akosobucka@wp.pl 
WHO data, only about $50 \%$ of chronically ill patients adhere strictly to the recommendations in developed countries. ${ }^{6}$

Nonadherence to medication regimen after myocardial infarction (MI) leads to increased morbidity and mortality and generates additional cost to the health care system. ${ }^{7-9}$ Unfortunately, nonadherence to treatment remains common and difficult to detect. In particular, cessation of antiplatelet treatment may lead to catastrophic ischemic events. According to our previously published study, only 54.3\% of patients adhered to treatment with clopidogrel during the first year after MI. ${ }^{7}$ Those who did not adhere to prescribed medication were 4-fold more likely to experience acute coronary syndrome again $(11.0 \%$ vs $2.8 \% ; P=0.044)$ and twice as prone to unscheduled cardiac hospitalization $(21.2 \%$ vs $9.9 \% ; P=0.04) .{ }^{8}$ In the Prospective Registry Evaluating Myocardial Infarction: Events and Recovery (PREMIER) registry among $500 \mathrm{MI}$ patients who were discharged on thienopyridine therapy, 68 (13.6\%) stopped medication within the first 30 days. Patients who discontinued therapy had a higher likelihood of death during the next 11 months (7.5\% vs $0.7 \%, P=0.0001$; adjusted hazard ratio [HR] 9.0; 95\% CI 1.3-60.6) and rehospitalization (23\% vs $14 \%$, $P=0.08$; adjusted HR 1.5; 95\% CI 0.78-3.0). ${ }^{9}$

The information on the completeness and determinants of adherence to recommended therapy seems to be crucial to improve the efficacy of treatment. ${ }^{10,11}$ Adherence assessment can be performed using direct and indirect methods. ${ }^{4,12,13}$ Due to the high costs, the use of direct methods is not a common way to monitor the therapy. The indirect method of adherence evaluation using self-reported questionnaires is a simple, cheap and easy method. Moreover, with this method, the medical staff can receive information regarding the causes of nonadherence, which allows them to individualize interventions aiming to modify the negative attitude of both the patients and the therapeutic team. ${ }^{4,12,13}$ The Adherence in Chronic Diseases Scale (ACDS) is a newly developed, validated method for assessment of adherence to treatment in chronically ill patients. So far, the ACDS has been used in relatively small groups of patients. ${ }^{14}$

The aim of the study was to evaluate the level of adherence to treatment using the ACDS in patients after MI. Furthermore, the impact of sociodemographic and clinical factors on ACDS scores was assessed.

\section{Patients and methods}

A single-center, prospective, observational cohort clinical study with a 6-month follow-up was performed according to the protocol approved by the Bioethics Committee of the Collegium Medicum, Nicolaus Copernicus University in
Torun (approval number KB 312/2015). The research was performed in accordance with the Declaration of Helsinki and was consistent with International Conference on Harmonization/Good Clinical Practice and applicable regulatory requirements.

Patients hospitalized for MI treated with percutaneous coronary intervention (PCI) were considered as potential candidates for enrollment into the study. Patients with physical or cognitive impairment, prisoners, soldiers, and family members and coworkers of the researchers were excluded from the study.

Patients were assessed for adherence 6 months after hospitalization for acute MI from May 2015 to July 2016. All participants gave written informed consent at the time of inclusion into the study. A standardized self-reported questionnaire - the ACDS (Table 1) - assessing the level of adherence to treatment recommendations in chronically ill adults was applied. ${ }^{8,11}$ The ACDS, our own tool, was developed by A Kubica and previously validated in patients with coronary artery disease (CAD) ${ }^{11}$ It is available free of charge on the website of the Department of Health Promotion, Collegium Medicum, Nicolaus Copernicus University, Poland (https://www.cm.umk.pl/wydzialy/wydzial-nauk-ozdrowiu/jednostki-wydzialowe/katedra-i-zaklad-promocjizdrowia.html). The questionnaire consists of seven questions with five variants of responses to each question. Questions 1-5 concern the patient behavior related to medication; questions 6 and 7 identify the physician-patient relationship, that indirectly affects adherence. Depending on the answer, each item of the scale is awarded 0-4 points. Adherence evaluation with ACDS was performed according to the score defined in the validation article. ${ }^{14}$ A score of $>26$ points

Table I Items of the Adherence in Chronic Diseases Scale (ACDS)*
I. Do you always take all your medications according to your doctor's instructions?
2. Do you ever change your medications' dosing without prior consultation with your doctor?
3. Do you adjust your medications' dosing according to how you feel?
4. What do you do on the appearance of medication-related side effects (eg, stomach pain, liver pain, rash, lack of appetite, edema)?
5. Do you find all your medications necessary for your health?
6. Does your doctor inquire about medication-related problems that you might possibly experience?
7. Do you tell the truth when asked by your doctor about medication- related problems?

Note: *Adapted from Kubica A, Kosobucka A, Michalski P, et al. The Adherence in Chronic Diseases Scale - a new tool to monitor implementation of a treatment plan. Folia Cardiol. 2017;12:19-26." And Kubica A. Adherence in Chronic Diseases Scale. Available from: https://www.cm.umk.pl/wydzialy/wydzial-nauk-o-zdrowiu/jednostkiwydzialowe/katedra-i-zaklad-promocji-zdrowia.html. Accessed July 10, 2017.34 Copyright (c) 2017 Aldona Kubica." 
reflects high adherence to treatment, while scores of 21-26 and $<21$ points, respectively, correspond to intermediate and low adherence. This tool not only reflects the actual implementation of the treatment plan in terms of pharmacotherapy, but also indicates the mechanisms that determine patient adherence. Patients were instructed that adherence evaluation regarded medication prescribed at discharge from hospital. All patients were treated according to the guidelines of European Society of Cardiology. ${ }^{15}$

The results of the ACDS were analyzed with regard to sociodemographic and clinical factors. The variables were collected based on an additional standarized questionnaire and the patient's medical records. The following sociodemographic factors were taken into consideration: gender, age, education, employment status, economic status, marital status, place of residence, living alone or with family. The analyzed clinical factors included: hypertension, hyperlipidemia, smoking, diabetes mellitus, family burden, and CAD, including: previous hospitalizations, $\mathrm{MI}, \mathrm{PCI}$, coronary artery bypass grafting (CABG). In order to ensure the accuracy and completeness of the collected data, patients were assured of anonymity and confidentiality with regard to the information obtained from the questionnaire. Researchers did their best not to influence the patients' responses.

The statistical analysis was performed using the Statistica 12.0 package (StatSoft Inc, Tulsa, OK, USA). Continuous variables were presented as medians with interquartile ranges and means with standard deviations. The Shapiro-Wilk test demonstrated non-normal distribution of the investigated continuous variables. Therefore, nonparametric tests were used for statistical analysis. Comparisons between two groups were performed with the Mann-Whitney unpaired rank sum test. For comparisons between three or more groups, the Kruskal-Wallis one-way analysis of variance was used. Differences were considered significant at $P<0.05$.

In order to identify factors with independent influence on the ACDS score, multiple regression analysis was performed. For identification of the best statistical model, backward stepwise regression was applied. Variables with a $P$-value of $<0.1$ in the univariate analysis were introduced into the multiple regression model. Subsequently, variables without significant impact $(P>0.05)$ were removed one after another from the multivariate model.

\section{Sample size calculation}

According to previously published data ${ }^{8}$ reporting $11.0 \%$ vs $2.8 \%$ incidence of ACS in patients nonadherent vs patients adherent to pivotal treatment after MI and assuming a two-sided alpha value of 0.05 , we calculated using the test for two fractions that enrollment of 199 patients would provide a $90 \%$ power to demonstrate a significant difference in the prevalence of ACS between high adherence patients (ACDS score $>26$ points) vs remaining subjects. Taking into account a $25 \%$ drop-out, we decided to enroll 250 patients in the study.

\section{Results}

Out of 379 consecutive patients who met the inclusion criteria during hospitalization, 252 individuals were enrolled in the study. The remaining 127 patients did not provide their consent for participation in the study. There were lacking clinical data from the follow-up period in 13 patients and 18 subjects did not provide complete answers for the ACDS questionnaire. The final study cohort comprised of 221 out of the 379 screened patients (63 women and 158 men) aged 30-91 years (average age 62.93 years), who answered all the questionnaire items. The adherence level assessed with the ACDS 6-months after hospitalization for MI ranged from 7 to 28 points, with an average score of 23.35 and median score of 24 points. The scores were classified as high ( $>26$ points), intermediate (21-26 points) and low ( $<21$ points), and were obtained by 59 (26.7\%), $110(49.8 \%)$ and $52(23.5 \%)$ patients, respectively.

Among the sociodemographic factors, age and employment status were found to have significant influence on the level of adherence to therapeutic recommendations. Patients under 65 years of age achieved higher ACDS scores, suggesting better adherence than in elderly subjects (24.31 vs 22.12 points, $P=0.0005$ ).

Higher ACDS scores were found in professionally active patients as compared with non-working individuals (unemployed, retired): 24.2 vs 22.78; $P=0.0276$. Limited group sizes did not allow statistical analysis according to economic status. No significant impact of other factors on the ACDS score was found (Table 2).

Patients with a previous diagnosis of CAD, hospitalization for CAD, MI, and PCI in the past achieved significantly lower ACDS scores. Patients with comorbidities (hypertension, hyperlipidemia, diabetes) were less likely to follow therapeutic recommendations, but no significant differences in terms of scoring were seen for any of these diseases in our study. We found no evidence of influence of any other clinical parameters on adherence assessed with the ACDS. Detailed results are presented in Table 2.

According to the multivariate analysis, only age and previous myocardial infarction influenced adherence to 
Table 2 Group characteristics and results of the ACDS according to selected clinical parameters and sociodemographic factors

\begin{tabular}{|c|c|c|c|c|c|}
\hline Parameter & Variable & $\begin{array}{l}\text { Total sample } \\
(n=22 I)\end{array}$ & Mean \pm SD & $\begin{array}{l}\text { Median } \\
\text { (QI-Q3) }\end{array}$ & $p$-value \\
\hline \multirow[t]{2}{*}{ Gender } & Female & $63(28.5 \%)$ & $23.06 \pm 5.10$ & $24.0(21.0-28.0)$ & 0.8 \\
\hline & Male & I58 (7|.5\%) & $23.46 \pm 3.69$ & $24.0(21.0-26.0)$ & \\
\hline \multirow[t]{2}{*}{ Age } & $<65$ & $124(56.1 \%)$ & $24.3 I \pm 3.30$ & $25.0(22.0-27.0)$ & 0.0005 \\
\hline & $\geq 65$ & 97 (43.9\%) & $22.12 \pm 4.74$ & $23.0(20.0-26.0)$ & \\
\hline \multirow[t]{4}{*}{ Education } & Primary & $28(12.7 \%)$ & $22.93 \pm 4.63$ & $23.5(20.0-27.5)$ & 0.8 \\
\hline & Vocational & 79 (35.7\%) & $23.53 \pm 3.75$ & $24.0(21.0-27.0)$ & \\
\hline & Secondary & $83(37.6 \%)$ & $23.05 \pm 4.4$ & $24.0(20.0-27.0)$ & \\
\hline & Higher & 31 (14.0\%) & $24.06 \pm 3.66$ & $24.0(23.0-27.0)$ & \\
\hline \multirow[t]{4}{*}{ Employment status } & Employed & $88(39.8 \%)$ & $24.20 \pm 3.40$ & $25.00(22.0-27.0)$ & 0.05 \\
\hline & Unemployed & $14(6.3 \%)$ & $24.79 \pm 2.42$ & $25.00(24.0-27.0)$ & \\
\hline & OAP & $90(40.7 \%)$ & $22.58 \pm 4.37$ & $23.00(20.0-26.0)$ & \\
\hline & DLA recipient & $29(13.1 \%)$ & $22.45 \pm 5.35$ & $24.00(20.0-26.0)$ & \\
\hline \multirow[t]{4}{*}{ Economic status } & Very good & $12(5.4 \%)$ & $24.33 \pm 2.35$ & $24.00(23.5-26.5)$ & NA \\
\hline & Acceptable & 197 (89.1\%) & $23.36 \pm 3.87$ & $24.00(21.0-26.0)$ & \\
\hline & $\mathrm{Bad}$ & 12 (5.4\%) & $22.25 \pm 8.21$ & $27.50(16.0-28.0)$ & \\
\hline & Very bad & $0(0.0 \%)$ & $0.0 \pm 0.00$ & $0.00(0.0-0.0)$ & \\
\hline \multirow[t]{3}{*}{ Place of residence } & City & II 4 (5I.6\%) & $23.33 \pm 4.24$ & $24.00(21.0-27.0)$ & 0.5 \\
\hline & Town & $46(20.8 \%)$ & $22.96 \pm 4.06$ & $24.00(20.0-27.0)$ & \\
\hline & Village & $6 \mathrm{I}(27.6 \%)$ & $23.67 \pm 4.02$ & $24.00(22.0-27.0)$ & \\
\hline \multirow[t]{3}{*}{ Marital status } & Unmarried & $23(10.4 \%)$ & $24.04 \pm 3.59$ & $24.0(21.0-28.0)$ & 0.1 \\
\hline & Married & I 68 (76.0\%) & $21.6 \pm 5.14$ & $21.0(18.0-26.0)$ & \\
\hline & Widowed & $30(13.6 \%)$ & $23.57 \pm 3.95$ & $24.0(21.5-27.0)$ & \\
\hline \multirow[t]{2}{*}{ Living status } & Alone & $27(12.2 \%)$ & $22.89 \pm 5.24$ & $24.0(20.0-28.0)$ & 0.1 \\
\hline & With family & 194 (87.8\%) & $23.4 I \pm 3.97$ & $24.0(21.0-27.0)$ & \\
\hline Prior hospitalization & Yes & $83(36.7 \%)$ & $23.91 \pm 3.6522$. & $24.5(21.0-27.0)$ & 0.03 \\
\hline for CAD & No & 138 (62.4\%) & $42 \pm 4.70$ & $23.0(20.0-26.0)$ & \\
\hline \multirow[t]{2}{*}{ History of CAD } & Yes & I0I (45.7\%) & $22.56 \pm 4.42$ & $23.0(20.0-26.0)$ & 0.01 \\
\hline & No & 120 (54.3\%) & $24.0 \mathrm{I} \pm 3.77$ & $25.0(22.0-27.5)$ & \\
\hline \multirow[t]{2}{*}{ Prior MI } & Yes & $62(28.1 \%)$ & $21.87 \pm 4.69$ & $22.0(20.0-25.0)$ & 0.002 \\
\hline & No & 159 (71.9\%) & $23.92 \pm 3.75$ & $25.0(22.0-27.0)$ & \\
\hline \multirow[t]{2}{*}{ Prior $\mathrm{PCl}$} & Yes & $8 \mathrm{I}(36.7 \%)$ & $22.5 I \pm 4.52$ & $23.0(20.0-26.0)$ & 0.03 \\
\hline & No & 140 (63.3\%) & $23.84 \pm 3.82$ & $24.0(21.0-27.0)$ & \\
\hline \multirow[t]{2}{*}{ Prior CABG } & Yes & $33(73.8 \%)$ & $22.79 \pm 3.16$ & $22.0(20.0-25.0)$ & 0.1 \\
\hline & No & $188(26.2 \%)$ & $23.45 \pm 4.28$ & $24.0(21.0-27.0)$ & \\
\hline \multirow[t]{2}{*}{ Hypertension } & Yes & I 63 (73.8\%) & $23.22 \pm 4.14$ & $24.0(20.0-27.0)$ & 0.4 \\
\hline & No & $58(26.2 \%)$ & $23.7 I \pm 4.13$ & $24.5(21.0-27.0)$ & \\
\hline \multirow[t]{2}{*}{ Hyperlipidemia } & Yes & I52 (68.8\%) & $23.15 \pm 4.20$ & $24.0(20.0-27.0)$ & 0.2 \\
\hline & No & $69(31.2 \%)$ & $23.78 \pm 3.99$ & $25.0(22.0-27.0)$ & \\
\hline \multirow[t]{3}{*}{ Smoking status } & Yes (current) & 78 (35.3\%) & $24.06 \pm 3.46$ & $25.0(22.0-27.0)$ & 0.1 \\
\hline & No (current) & 143 (64.7\%) & $22.96 \pm 4.42$ & $24.0(20.0-27.0)$ & \\
\hline & Ex-smoker & $5 \mathrm{I}(58.4 \%)$ & $23.78 \pm 3.55$ & $24.0(21.0-27.0)$ & \\
\hline \multirow[t]{2}{*}{ Family burden } & Yes & 132 (59.7\%) & $23.58 \pm 3.74$ & $24.0(21.0-27.0)$ & 0.6 \\
\hline & No & 89 (40.3\%) & $23.00 \pm 4.66$ & $24.0(20.0-27.0)$ & \\
\hline
\end{tabular}

Notes: City >100,000 inhabitants; town $\leq 100,000$ inhabitants.

Abbreviations: ACDS, Adherence in Chronic Diseases Scale; Q, quartile; OAP, old age pensioner; DLA, Disability Living Allowance; NA, non analyzed; CAD, coronary artery disease; $\mathrm{MI}$, myocardial infarction; $\mathrm{PCl}$, percutaneous coronary intervention; CABG, coronary artery bypass grafting; SD, standard deviation.

treatment assessed with the ACDS (Table 3), explaining the $10.3 \%$ variability observed with the ACDS.

The analysis of answers for each ACDS item showed that patients under 65 years of age had significantly higher scores in all, but item number 6 (Table 4). Employment status differentiated patients in terms of responses to the majority of items, except for items 4 and 6 . The lowest scores were obtained by old age pensioners and disability living allowance recipients. Unmarried patients declared the highest adherence to recommended pharmacotherapy (item 1), while those remaining in a relationship were most likely to be convinced that all prescribed medications should 
Table 3 The impact of clinical parameters and sociodemographic factors on the ACDS score - multivariate analysis

\begin{tabular}{|c|c|c|c|c|c|}
\hline \multirow[t]{2}{*}{ Parameter } & \multicolumn{5}{|c|}{ Model characteristics: $R=0.32 I ; R^{2}=0.103 ; P=0.000007$} \\
\hline & $\beta$ coefficient & $\begin{array}{l}\beta \text { coefficient } \\
\text { SD }\end{array}$ & $\begin{array}{l}\text { Direction } \\
\text { component } \beta\end{array}$ & $\begin{array}{l}\text { Direction } \\
\text { component } \beta \text { SD }\end{array}$ & $p$-value \\
\hline Intercept & & & 24.680 & 0.3762 & $<0.0001$ \\
\hline Age $\geq 65$ & -0.2331 & 0.0650 & -1.937 & 0.5398 & 0.0004 \\
\hline Prior MI & -0.1869 & 0.0650 & -1.715 & 0.5963 & 0.0044 \\
\hline
\end{tabular}

Note: $\beta$-coefficient - the standardized coefficient is what the regression coefficient would be if the model fitted to standardized data.

Abbreviations: ACDS, Adherence in Chronic Diseases Scale; MI, myocardial infarction; SD, standard deviation.

be taken in order to maintain good health (item 5). Other sociodemographic factors had no impact on the responses to individual ACDS items (Table 4).

A previous diagnosis of CAD or hospitalization for $\mathrm{CAD}, \mathrm{MI}$, and earlier PCI were consistently associated with numerically lower scores in all ACDS items, with some differences being statistically significant (Table 4). Moreover, patients with hypertension more frequently than others adjusted their medication dosage according to how they felt (item 3). Furthermore, patients with diabetes tended to change their medications dosage more frequently without consulting with their doctor (item 2). No differences were found regarding other analyzed clinical factors.

Among the 221 patients constituting the final study cohort, $18(8.1 \%)$ experienced subsequent acute coronary syndrome (re-ACS) during the follow-up period. Numerically lower ACDS scores were shown in re-ACS patients as compared with the remaining subjects $(22.61 \pm 3.96$ vs $23.52 \pm 4.02$; $P=0.3$ ). The prevalence of re-ACS was $11.1 \%$ in high-level adherence subjects (ACDS score $>26$ points) and 28.4\% in patients with lower ACDS score $(P=0.1)$. Significantly lower scores in this subset of patients were found for item 2 and 3: $3.11 \pm 0.68$ vs $3.45 \pm 0.73(P=0.02)$ and $3.28 \pm 0.89$ vs $3.64 \pm 0.64(P=0.04)$, respectively.

\section{Discussion}

MI patients adherent to treatment are at low risk of ischemic complications and premature death. ${ }^{7,16}$ According to our results, patients with MI treated with PCI, especially those with prior MI and older age, were associated with lower adherence to prescribed medication after discharge, defining the subsets of patients requiring additional intervention during the planning and implementation of the treatment plan.

Subjects with hypertension more frequently than others adjusted their medication dosage according to how they felt (ACDS item 3) and those with diabetes tended to change their medications dosage more frequently without consulting their doctor (ACDS item 2). Lower scores for both these ACDS

Table 4 The impact of sociodemographic factors and clinical parameters on scores obtained for each ACDS item

\begin{tabular}{llllllll}
\hline Parameter & Q I & Q2 & Q3 & Q4 & Q5 & Q6 & Q7 \\
\hline Gender & 0.06 & 0.5 & 0.06 & 0.2 & 0.9 & 0.3 & 0.4 \\
Age & 0.0006 & 0.0033 & 0.0022 & 0.0208 & 0.0037 & 0.309 & 0.0022 \\
Education & 0.9 & 0.1 & 0.3 & 0.4 & 0.3 & 1.0 & 0.2 \\
Employment status & 0.0324 & 0.0222 & 0.0167 & 0.5 & 0.0162 & 0.6 & 0.0376 \\
Economic status & 0.5 & 0.5 & 0.4 & 1.0 & 1.0 & 0.3 & 0.8 \\
Place of residence & 0.7 & 0.9 & 0.6 & 0.4 & 0.8 & 0.4 & 0.4 \\
Marital status & 0.0176 & 0.1 & 0.1 & 0.2 & 0.0350 & 0.6 & 0.1 \\
Living status & 1.0 & 0.8 & 0.4 & 0.3 & 0.197 & 0.7 & 0.8 \\
Hospitalization for CAD & 0.0218 & 0.0125 & 0.4 & 0.2 & 0.4 & 0.0274 \\
Prior CAD & 0.2 & 0.0056 & 0.2 & 0.0140 & 0.2 & 0.0309 \\
Prior MI & 0.0325 & 0.0201 & 0.0270 & 0.0016 & 0.1 & 0.0 & 0.2 \\
Prior PCI & 0.4 & 0.0226 & 0.4 & 0.0254 & 0.5 & 0.1 & 0.2 \\
Prior CABG & 0.9 & 0.1 & 0.5 & 0.2 & 0.3 & 0.8 \\
Hypertension & 0.4 & 0.2 & 0.0285 & 0.5 & 0.6 & 0.9 & 0.3 \\
Hyperlipidemia & 0.1 & 0.5 & 0.7 & 0.8 & 0.3 & 0.5 \\
Smoking status & 0.4 & 0.2 & 0.7 & 0.3 & 0.6 & 0.1 \\
Family history & 0.2 & 0.7 & 0.8 & 0.1 & 0.5 & 0.1 \\
Diabetes & 0.5 & 0.0143 & 0.6 & 0.4 & 0.6 & 0.1 \\
\hline
\end{tabular}

Abbreviations: ACDS, Adherence in Chronic Diseases Scale; Q, quartile; CAD, coronary artery disease; MI, myocardial infarction; PCl, percutaneous coronary intervention; CABG, coronary artery bypass grafting. 
items were associated with increased risk of re-ACS during follow-up, suggesting predictive value of these items. This finding, however, needs to be confirmed in further studies. Moreover, our findings showing a relationship between risk for adverse events and two specific ACDS items indicate an essential area of educational interventions.

In our study, high adherence level as defined by ACDS score was found in $26.7 \%$ of patients, intermediate in $49.8 \%$, and low in $23.5 \%$ of patients. Naderi et al in a meta-analysis of 20 studies (376,162 patients) defined the adherence rate of patients treated for primary and secondary prevention of cardiovascular disease (CVD) to be $50 \%$ and $66 \%$, respectively. ${ }^{17}$ Ho et $\mathrm{al}^{7}$ reported that in a population of 1,521 patients discharged from hospital after MI, at 1 month, one in three did not follow strictly therapeutic recommendations. Patients with previous MI are prone to stop antiplatelet therapy usually soon after the beginning of treatment. The discontinuation rate in the Prevention of Cardiovascular Events in Patients With Prior Heart Attack Using Ticagrelor Compared to Placebo on a Background of Aspirin-Thrombolysis in Myocardial Infarction 54 (PEGASUS-TIMI 54) trial ranged from $29 \%$ to $32 \%$ over the 33 months follow-up and the median time to discontinuation of treatment was between 55 and 103 days. ${ }^{18}$ Cessation of treatment with ticagrelor was mostly driven by nonserious adverse events occurring primarily early after randomization. ${ }^{18,19}$ Therefore, additional educational intervention aimed to improve adherence to treatment should be applied in patients with diagnosed high risk of nonadherence. Explanation of nonthreatening side effect mechanisms and risks associated with discontinuation of pivotal medication may improve adherence rate.

Our study confirms the usefulness of ACDS as a diagnostic tool for the identification of patients of high risk of nonadherence to pivotal treatment after MI. Moreover, it provided data showing ACDS as a promising method that may be applied for the prediction of adverse clinical events.

The WHO identifies five groups of determinants of adherence to prescribed treatment: socioeconomic factors, treatment-related factors, patient-related factors, factors related to the health care system (including health care system workers), and illness-related factors. ${ }^{6,20}$ Such definition reflects the complexity of the phenomenon of adherence to treatment as well as the multitude of areas that may require intervention.

Several reports pointing at older age ${ }^{16,21,22}$ and female gender ${ }^{22,23}$ as determinants of low adherence in patients with CAD including MI survivors, were partly confirmed in our study. A higher prevalence of cognitive disorders, memory impairment, and limited ability to absorb new information in the elderly population are associated with lower adherence. ${ }^{21}$ Furthermore, the increase in comorbidity commonly seen with advancing age results in the need for polypragmasy, which is considered to be a factor adversely affecting adherence to treatment. ${ }^{23,24}$ Due to differences of cultural, social, and medical nature, there are different adherence determinants for distinct populations. In a previously published study ${ }^{25}$ in a relatively young study population after MI, adherent patients tended to be older. This observation was in line with some other analyses showing younger age, prior use of clopidogrel, comorbid conditions such as diabetes and chronic pulmonary disease, prior hospitalization and prior PCI to have a negative impact on adherence. ${ }^{26}$ On the other hand, Tuppin et $\mathrm{al}^{27}$ reported that adherence to evidencebased treatment was decreased significantly by age greater than 74 years, comorbidities and full health care coverage for low earners. According to our observations, the lower adherence to treatment in the elderly population, as assessed with ACDS, results from the fact that elderly people are more likely to forget to take all their medication and to adjust the dosage according to how they feel, and are less convinced about the need for taking all recommended medications.

Men, as compared to women, declared to be more systematic in taking all medication in accordance with their doctor's instructions, but this observation had no significant impact on the overall score.

The impact of a patient's education level on adherence remains a subject of discussion. According to the data published by Ho et $\mathrm{al}^{7}$ in the PREMIER study, MI patients without higher education were more likely to discontinue their medication, however according to other researchers, this factor was not relevant. ${ }^{28,29}$ In our observation, the impact of education level was not significant. Nevertheless, it is worth pointing out that people with higher education obtained a slightly higher ACDS score, suggesting better adherence.

Professionally active patients responding to ACDS items were more likely to remember to take all medication, not to modify the dosage without the doctor's consultation, and to accept the need for taking all prescribed drugs for health support. This resulted in a higher overall score, reflecting better adherence to recommended treatment as compared with non-working subjects.

Family support may help patients to follow the therapeutic plan. Sayers et $\mathrm{al}^{30}$ in a study of patients after MI assessed with the Scale of Perceived Social Support tool for the level of emotional and instrumental support received from loved 
ones and its impact on adherence, reported a positive effect of receiving emotional support on adherence to treatment. In addition, Wu et $\mathrm{al}^{31}$ have shown that lack of family support was regarded by patients with heart failure as a factor impeding the realization of the therapeutic plan. The analysis of our data does not support this observation, as neither the marital status nor "living alone" or "with family" have influenced the overall ACDS score despite the significant differences in single ACDS items scoring.

Interestingly, our data reveal an unexpected effect of clinical parameters on the ACDS score. Patients with previously diagnosed CAD, previously hospitalized due to $\mathrm{CAD}$, after $\mathrm{MI}$ and after revascularization, presented a lower level of adherence to therapeutic recommendations. These results can and should be a cause of concern. One can expect that every subsequent hospitalization due to CAD should improve the understanding of the essence of the disease and motivate patients to improve their adherence to recommended therapy. Meanwhile, in the study population we observed the opposite phenomenon. Low adherence to recommended treatment may have contributed to an increased risk of recurrent ischemic events; however, patients who were hospitalized again were educated according to the same protocol as those who were admitted to hospital for the first time due to CAD. Thus, the level of knowledge and motivation for effective treatment in rehospitalized patients should be greater or at least the same as in first-time comers. The results suggest that the recurrence of major adverse cardiovascular events should prompt medical staff to pay special attention and apply personalized care including educational intervention to improve adherence to treatment. Bagchi et al reported that in patients with CVD additional in-hospital education improved adherence to therapeutic recommendations during follow-up. ${ }^{32}$

Patients with concomitant hypertension, hyperlipidemia or diabetes had numerically lower scores, however the differences were not statistically significant. The opposite could be expected, as patients with multiple chronic illnesses are expected to follow complex treatment regimens, monitor their condition, make lifestyle changes, and undertake decisions regarding the need for professional help. Functioning in the role of self-manager, particularly when living with chronic illness, requires a high level of knowledge, skill, and confidence. The Patient Activation Measure (PAM) has been described as an effective tool providing insight into possible strategies for supporting activation among patients. ${ }^{33}$ The use of PAM may supplement ACDS assessment allowing a more complete assessment of the patient's needs.
The failure to follow treatment recommendations in patients after MI may be catastrophic. Nonadherence to treatment results in therapeutic failures, increased complications rate, and rising costs of treatment. The ACDS-based identification of patients at high risk for nonadherence and its causes allows the implementation of personalized strategies for adherence improvement including educational interventions

\section{Limitations and strengths of the study}

The search for methods of adherence assessment that are both effective and easy to apply remains a challenge. The ACDS questionnaire applied in this study is a newly developed and relatively poorly studied research tool. No objective, direct method of a patient's medication-taking behavior assessment was used to verify the results obtained with a self-reported questionnaire. Nevertheless, despite obvious limitations of the ACDS related to the characteristic features of this kind of tool, it allows us to assess the risk of nonadherence and helps to determine specific obstacles to medication adherence. Moreover, the uniformity of the study population in terms of diagnosis and treatment, with a low drop-out proportion, strengthens the credibility of the obtained results.

Taking into account these previously mentioned limitations, further studies with direct verification of adherence levels as well as studies analyzing the potential impact of the ACDS results on long-term clinical outcome are needed.

\section{Conclusion}

High adherence to treatment according to the ACDS score was observed in approximately $25 \%$ of patients 6 -months after MI. Age and prior MI were identified as factors influencing the level of adherence to therapeutic recommendations.

\section{Acknowledgments}

The authors wish to thank all the patients who participated in this study.

\section{Author contributions}

All authors contributed toward data analysis, drafting and critically revising the paper, gave final approval of the version to be published, and agree to be accountable for all aspects of the work.

\section{Disclosure}

The authors report no conflicts of interest in this work. 


\section{References}

1. World Health Organization (WHO). Mortality and global burden of disease. Available from: http://www.who.int/gho/mortality_burden_ disease/en/. Accessed July 10, 2017.

2. Nichols M, Townsend N, Scarborough P, Rayner M. Cardiovascular disease in Europe 2014: epidemiological update. Eur Heart J. 2014;35: 2950-2959.

3. Kubica A, Grześk G, Sienkiewicz W, Kozinski M, Grześk E, Goch A. [Compliance, concordance, adherence in chronic disease]. Folia Cardiol Excerpta. 2010;5:54-57. Polish.

4. Jeffery B, Navarro T, Wilczynski NL, et al. Adherence measurement and patient recruitment methods are poor in intervention trials to improve patient adherence. J Clin Epidemiol. 2014;67:1076-1082.

5. Haynes RB, McDonald HP, Garg AX. Helping patients follow prescribed treatment: clinical applications. JAMA. 2002;288:2880-2883.

6. Sabaté E (ed.). Adherence to long-term therapies: evidence for action. Geneva: World Health Organization; 2003.

7. Ho PM, Spertus JA, Masoudi FA, et al. Impact of medication therapy discontinuation on mortality after myocardial infarction. Arch Inter Med. 2006;166:1842-1847.

8. Kubica A, Obonska K, Kasprzak M, et al. Prediction of high risk of nonadherence to antiplatelet treatment. Kardiol Pol. 2016;74(1):61-67.

9. Spertus JA, Kettelkamp R, Vance C, et al. Prevalence, predictors, and outcomes of premature discontinuation of thienopyridine therapy afterdrug-eluting stent placement: results from the PREMIER registry. Circulation. 2006;113(24):2803-2809.

10. Kubica A, Kasprzak M, Obońska K, et al. Discrepancies in assessment of adherence to antiplatelet treatment after myocardial infarction. Pharmacology. 2015;95:50-58.

11. Kubica A, Kosobucka A, Michalski P, et al. The Adherence in Chronic Diseases Scale - a new tool to monitor implementation of a treatment plan. Folia Cardiol. 2017;12:19-26.

12. De las Cuevas C, Penate W. Psychometric properties of the eight-item Morisky Medication Adherence Scale (MMAS-8) in a psychiatric outpatient setting. Int J Clin Health Psychol. 2015;15:121-129.

13. Osterberg L, Blaschke T. Adherence to medication. N Engl J Med. 2005; 353:487-497.

14. Buszko K, Obońska K, Michalski P, et al. The Adherence Scale in Chronic Diseases (ASCD). The power of knowledge: the key to successful patient-health care provider cooperation. Med Res J. 2016;1: $37-42$.

15. Steg PG, James SK, Atar D, et al. On behalf of the European Society of Cardiology Task Force. ESC Guidelines for the management of acute myocardial infarction in patients presenting with ST-segment elevation. Eur Heart J. 2012;33:2569-2619.

16. Simpson RJ. Challenges for improving medication adherence. JAMA. 2006;296:2614-2616.

17. Naderi SH, Bestwick JP, Wald DS. Adherence to drugs that prevent cardiovascular disease: meta-analysis on 376,162 patients. Am J Med. 2012;125:882-887.

18. Bonaca MP, Bhatt DL, Cohen M, et al. PEGASUS-TIMI 54 Steering Committee and Investigators. Long-term use of ticagrelor in patients with prior myocardial infarction. N Engl J Med. 2015;372:1791-1800.
19. Kubica J, Adamski P, Buszko K, et al. Rationale and design of the effectiveness of lower maintenance dose of ticagrelor early after myocardial infarction (ELECTRA) pilot study. Eur Heart $J$ Cardiovasc Pharmacother. Epub October 10, 2017.

20. Kardas P, Lewek P, Matyjaszczyk M. Determinants of patient adherence: a review of systematic reviews. Front Pharmacol. 2013;4:91.

21. Sattler ELP, Lee JS, Perri M III. Medication (re)fill adherence measures derived from pharmacy claims data in older Americans. A review of the literature. Drugs Aging. 2013;30:383-399.

22. Cotter G, Shemesh E, Zehavi M, et al. Lack of aspirin effect: aspirin resistance or resistance to taking aspirin? Am Heart J. 2004;147:293-300.

23. Granger BB, Ekman I, Granger CB, et al. Adherence to medication according to sex and age in the CHARM programme. Eur J Heart Fail. 2009;11:1092-1098.

24. Cholowski K, Cantwell R. Predictors of medication compliance among older heart failure patients. Int J Older People Nurs. 2007;2: 250-262.

25. Kubica A, Kasprzak M, Siller-Matula J, et al. Time-related changes in determinants of antiplatelet effect of clopidogrel in patients after myocardial infarction. Eur J Pharmacol. 2014;742:47-54.

26. Zhu B, Zhao Z, McCollam P, et al. Factors associated with clopidogrel use, adherence, and persistence in patients with acute coronary syndromes undergoing percutaneous coronary intervention. Curr Med Res Opin. 2011;27(3):633-641.

27. Tuppin P, Neumann A, Danchin N, et al. Evidence-based pharmacotherapy after myocardial infarction in France: adherence-associated factors and relationship with 30-month mortality and rehospitalization. Arch Cardiovasc Dis. 2010;103(6-7):363-375.

28. Wu JR, Moser DK, Chung ML, Lennie TA. Predictors of medication adherence using a multidimensional adherence model in patients with heart failure. J Card Fail. 2008;14:603-614.

29. Evangelista LS, Berg J, Dracup K. Relationship between psychosocial variables and compliance in patients with heart failure. Heart Lung. 2001;30:294-301.

30. Sayers SL, Riegel B, Pawlowski S, Coyne JC, Samaha FF. Social support and self-care of patients with heart failure. Ann Behav Med. 2008;35:70-79.

31. Wu JR, Chung M, Lennie TA, Hall LA, Moser DK. Testing the psychometric properties of the Medication Adherence Scale in patients with heart failure. Heart Lung. 2008;37:334-343.

32. Bagchi AD, Esposito D, Kim M, Verdier J, Bencio D. Utilization of, and adherence to, drug therapy among Medicaid beneficiaries with congestive heart failure. Clin Ther. 2007;29:1771-1783.

33. Hibbard JH, Mahoney ER, Stockard J, Tusler M. Development and testing of a short form of the patient activation measure. Health Serv Res. 2005;40(6 Pt 1):1918-1930.

34. Kubica A. Adherence in Chronic Diseases Scale. Available from: https:// www.cm.umk.pl/wydzialy/wydzial-nauk-o-zdrowiu/jednostki-wydzialowe/katedra-i-zaklad-promocji-zdrowia.html. Accessed July 10, 2017.

\section{Dovepress}

\section{Publish your work in this journal}

Patient Preference and Adherence is an international, peer-reviewed, open access journal that focuses on the growing importance of patient preference and adherence throughout the therapeutic continuum. Patient satisfaction, acceptability, quality of life, compliance, persistence and their role in developing new therapeutic modalities and compounds to optimize

clinical outcomes for existing disease states are major areas of interest for the journal. This journal has been accepted for indexing on PubMed Central. The manuscript management system is completely online and includes a very quick and fair peer-review system, which is all easy to use. Visit http://www dovepress.com/testimonials.php to read real quotes from published authors. 